\title{
THE BINDING CREDIT CONSTRAINTS AND THE WELFARE EFFECTS OF HOUSING PRICE APPRECIATION
}

\author{
Ashot Tsharakyan, Martin Janíčko*
}

\begin{abstract}
:
The paper deals with some relevant effects of appreciation of housing prices on social and aggregate welfare. As it has been found difficult to assess the current situation given the housing market being the most affected by the crisis, earlier data from 1995 to 2006 have been used. It generalizes previously available results by considering credit constraints together with endogeneity of housing prices. First, housing price appreciation implies improvement in aggregate welfare in a model with exogenous housing price and credit constraints. Then, housing price is endogenized by modelling the supply side of the housing market. In this model, housing price appreciation is caused by supply and demand shocks. The supply shock originates from a change in building permit cost. The demand shifts are generated by changes in household income and interest rates. Both credit-constrained and unconstrained versions of this model are considered. Finally, the combination of observed demand and supply shocks is used to quantify aggregate welfare effects on the US housing market. The results demonstrate that demand shocks dominated during that period and the aggregate welfare improved as a result of housing price appreciation.
\end{abstract}

Keywords: binding credit constraints, housing price appreciation, social welfare, aggregate welfare, endogenous housing price, demand and supply side shocks

JEL Classification: R2, R20, R21, R31

\section{Introduction}

In the second half of the 1990s and the first half of 2000s a considerable increase in housing prices was observed in majority of developed countries. Particularly in the United States housing prices have risen at a rate exceeding the growth rate of income and other asset prices during the last decade (Bajari et al., 2005; Li and Yao, 2005). Between 1985 and 1995, the increase in housing prices was 26.5\%, as opposed to $52.9 \%$ for the period from 1996 to 2006, using the constant-quality housing price index published by the US Census Bureau. This has stimulated research on the effects of housing price appreciation, particularly its link with monetary policy, its role in the business cycle and most importantly, its effects on consumption and consumer welfare

* Ashot Tsharakyan, CERGE-EI (atsharak@cerge-ei.cz); Martin Janíčko, University of Economics, Prague (martin.janicko@vse.cz). The earlier version of the paper was already published as the CERGE-EI internal working paper in 2007. In comparison with it this paper has been updated and contains several important changes. 
(see for example Iacoviello and Minetti, 2003; Lenhert, 2004; Iacoviello, 2005; Li and Yao, 2005; Campbell and Cocco, 2005; Bajari et al., 2005).

Some papers have studied the effects of the increase in housing prices on the consumption and welfare of separate groups, such as young renters, young homeowners and old homeowners. For example, Campbell and Cocco (2005) use UK micro-level data on real non-durable consumption growth and real housing price growth together with a life-cycle model to demonstrate a positive effect of an increase in the growth rate of housing prices on the growth rate of consumption. This effect is especially strong and significant for old homeowners and, still quite significant but smaller in magnitude, for young homeowners. Li and Yao (2005) also employ a life-cycle model of housing tenure choice to explore the effects of housing price shocks on household consumption and welfare. They find that for the homeowners less than 40 years old a permanent increase in housing price implies welfare losses while in case of older homeowners it implies an increase in their real non-durable consumption as well as welfare.

Bajari et al. (2005) study the aggregate effects of housing price changes on consumer welfare. They develop a new approach to measuring the changes in consumer welfare due to changes in the prices of owner-occupied housing. This approach defines welfare adjustment as the transfer in the form of income required to keep expected discounted utility constant, given the change in housing prices. The authors claim that this measure is more accurate than the user cost employed in earlier studies. The reason is that the user cost (defined as the marginal rate of substitution between housing and non-durable consumption) is entirely static while the welfare adjustment involves dynamics. In addition, user costs fail to take into account the role of housing as an investment good. Using their measure of welfare adjustment, the authors show that there is no change in aggregate welfare due to an increase in the price of the existing stock of housing. This result is based on a simple market clearing condition, which implies that the losses of buyers are exactly compensated by the gains of sellers. This conclusion holds for both a deterministic version of the model where current state conveys no information about future states, as well as for a stochastic one, where the state follows a first order Markov chain.

Bajari et al. (2005) abstract from rental markets and binding credit constraints. However, for households subject to binding credit constraints, housing appreciation implies two kinds of effects: i) an increase in lifetime housing costs because of the necessity to buy a larger house in the future; ii) a benefit due to a relaxation of credit constraints (because of increased housing equity) and thus the opportunity for better consumption smoothing. Thus, by abstracting from credit constraints, Bajari et al. (2005) ignore the additional effects, which housing price appreciation has on credit-constrained households. Empirically, one can evaluate the importance of credit constraints from the fact that over $65 \%$ of owner-occupied housing in US is mortgage-financed (according to American Housing Survey). From the modelling perspective, Ortalo-Magne and Rady (2005) identify a crucial role of capital gains and losses experienced by credit-constrained individuals in explaining housing market fluctuations. In the first part of this paper, the aggregate welfare effects of housing price appreciation are studied in a model analogous to Bajari et al. (2005) but with households subject to binding credit constraints. This assumption is based on the observation that 
in the period of substantial housing price appreciation substantial part of households in US was borrowing up to maximum available limit. In particular according to Monthly Interest Rate Survey of the Federal Housing Finance Agency between 1995 and 2006 on average around $48 \%$ of conventional single family mortgages taken per year in US had loan-to-value ratio equal to or very close to maximum loan-to-value ratio. Two major forms of credit constraint have been used in the previous literature. One of the most widely used models of credit constraints is that of Kiyotaki and Moore (1997). The authors study how credit constraints interact with aggregate economic activity over the business cycle. In this model, borrowing is restricted so that the repayment of a loan in the next period does not exceed the next period's value of the asset serving as collateral. Similar borrowing constraints are used by Iacaviello and Minneti (2003), Iacoviello (2004), etc. A more efficient form of credit constraint, called a margin clause, is considered by Mendoza and Durdu (2004). They employ collateral constraints under which the borrowing of a small open economy cannot exceed a fraction of the current market value of the economy's equity holdings. This type of contract is more effective and is widely used in international capital markets by investment banks and other lenders as a mechanism to manage default risk. In contrast to the Kiyotaki-Moore constraint, the custody of collateral assets is transferred at the time of entering into a credit contract (in Kiyotaki-Moore model it is transferred only in the next period, which is why it limits borrowing to the value of the asset in that period). Moreover, there is more flexibility and less risk for lenders since they can automatically make up shortfalls in the value of the collateral asset by liquidating it as soon as the price changes so that the value of the collateral is exactly equal to the debt. Presented results show that in an economy with binding credit constraints housing price appreciation implies an overall improvement in aggregate welfare. In a model with the Kiyotaki-Moore type constraint, this result holds only with the additional assumption that housing prices follow a random walk. In the model with a margin clause this result is observed even in the simplest deterministic version. This is due to the fact that the margin clause constraint is immediately affected by the housing price appreciation as the current price enters this constraint. However, if Kiyotaki-Moore constraint is used, the next period's price enters the constraint and it is not necessarily affected by the change in current price.

In Bajari et al. (2005), the housing prices are exogenous. In contrast, we allow housing price to be determined by the equilibrium in the housing market and to change due to supply-side and demand-side shocks. Modelling of the supply side shock follows primarily Glaeser and Guyourko (2005). They show that the increase in housing prices since the 1970s mainly reflects an increasing difficulty of obtaining regulatory approval for building houses. This can be explained by changing judicial tastes, decreasing ability to bribe regulators, and stricter formal procedures. Similarly, in our model an endogenous supply shock is generated by an increase in building permit costs. Besides analyzing the consequences of housing price appreciation driven by supply-side shocks, the theoretical model is used to explore the consequences of housing price appreciation driven by demand-side shocks. Inspection of the US data allows one to identify changes in income and interest rates as the most important demand-side shocks observed during 1995-2006. The effects of demand and supplyside shocks are analyzed for both credit constrained and unconstrained versions of the 
model. The results of the endogenous price model demonstrate that the final welfare effect of housing price appreciation depends on its source. Housing price appreciation driven by negative supply-side shocks such as increase in building permit cost leads to welfare loss, while housing price appreciation driven by positive demand-side shocks, such as increase in income or decrease in the interest rates implies a welfare gain. Comparison of welfare adjustments in a constrained and unconstrained model resulting from change in the building permit costs reveals that the relationship between them depends on the relative weight of housing in the utility function (under Cobb-Douglas form of preferences). Finally, the credit-constrained and unconstrained models are calibrated using a combination of actual demand and supply shocks in the US housing market in 1995-2004. The result demonstrates that housing price appreciation leads - other things held equal - to an improvement in aggregate welfare. The presented results are related to the period before crisis which was characterized by considerable housing price appreciation, situation different from the current post crisis situation in the housing market. However, the analysis presented here illustrates an important point, which is very relevant for the reasons that caused financial crisis and brought to current situation on the financial and housing markets (similar reasoning is to be found e.g. in Aghion and Bachetta (2004) or in Tsaratonis, Zhu (2004). Essentially it can be seen that effect of relaxation of credit constraints was crucial for welfare improvement which American households received in the observed period. However, such welfare improvement and continuous additional borrowing against the value of housing equity was sustainable only in case of continuous increase in housing prices. Similar to the households in the model economy in this paper, major part of American households was borrowing more and more money against the housing equity based on rising incomes and myopic presumption that the value of their housing equity will not fall in the near future and so it will be possible to continue consuming more and repay the debt. On the other hand, promoted by corresponding governmental policies and seemingly proliferate profit opportunities the banks were lending money to many people who actually could not afford it and, what's more, were completely unaware of the consequences this would have. While the bankers, with the help of the government, managed to increase the set of borrowers, increases in inflation also occurred. The economic planners did not expect it; it had not shown up in their math. The so called cheap money policy helped the mortgage/subprime crisis proliferate and amplified its impact. The equations turned back into words through policy. However, when incomes started to decline and situation with housing price changed radically many credit-constrained households which were borrowing and refinancing up to the limit, found themselves subject to much tighter credit constraints due to high accumulated debt, falling incomes and falling housing equity. In the context of present model, the substantial increase in the degree of being credit constrained would mean a substantial welfare loss for the households which could hardly be covered by somewhat lower lifetime housing costs. We did not include into analysis the period of crisis in the housing market due to the fact that taking into account complexity and deepness of crisis in the housing market in 2007-2009 it is quite hard task to build a model which would comprehensively and successfully describe situation in the market during the those years. This should not, however, pose any substantial complications regarding the paper. The main motive for us to say this is that it has above all an intention to 
analyze reality as well as it strives to show some inherent problems due to complexity of the phenomena.

The rest of the paper is organized a follows. Section 2 describes and solves the proposed model with households facing credit constraints and interprets the results. Section 3 builds and solves the model with endogenous housing price in both creditconstrained and unconstrained versions. Section 4 derives, interprets and compares welfare implications of housing price appreciation driven by supply side shocks. Section 5 analyzes the welfare implications of housing price appreciation driven by demand side shocks. Section 6 determines the change in aggregate welfare due to housing price appreciation driven jointly by the considered supply side and demand side shocks. Section 7 concludes the paper.

\section{The Model with Exogenous Housing Price and Credit Constraints}

\subsection{Model Definition and Solution}

Let us consider an economy subject to credit constraints in which there are two goods: a composite consumption good $c$ and housing $h$ with relative price $q$. Also, there are risk free assets in the form of bonds $b$. Households choose how many bonds to carry into next period $b_{t+1}\left(b_{t+1}\right.$ can be either positive or negative. In the latter case households are borrowers), how much housing consumption to carry into the next period $h_{t+l}$, and how much to consume now $c_{t}$. A household's investment into housing is denoted by $x_{t}$, and investment into the risk free asset (saving) is denoted by $s_{t}$. Households have real income $y_{t}$, and the interest rate paid for borrowing or received for investment in bonds is exogenous and given by $i_{t}$. Inflation is constant at the rate $\pi$. Adjustment of housing stock implies transaction costs which enter into the budget constraint as a separate expenditure $f 1\left\{x_{t} \neq 0\right\}$. Here $f 1$ is an operator which takes fixed positive value when steady state investment into housing is not equal to zero and value zero when investment into housing is equal to zero. In this version of the model, the depreciation of housing and new construction is abstracted from and it is assumed that there is a fixed stock of housing traded between the agents.

Households are credit constrained in the sense that they can borrow only up to a certain amount to finance their housing investment. Under margin clause constraint (Mendoza and Durdu, 2004) households can borrow only up to some fraction of their current wealth. In the present model, a household's current wealth consists of the current value of its housing stock which can be used as collateral. Thus, the credit constraint takes the form $b_{t+1} \geq-m q_{t} h_{t+1}$ i.e. households can borrow only up to fraction $\mathrm{m}<1$ of the total value of their housing stock.

The problem of the household can be formulated in the following way:

$$
\begin{gathered}
V\left(h_{t}, b_{t}, q_{t}, y_{t}\right)=\max \left\{u\left(c_{t}, h_{t}\right)+\beta V\left(h_{t+1}, b_{t+1}, q_{t+1}, y_{t+1}\right)\right\} \\
\left\{\mathrm{c}_{\mathrm{t}}, \mathrm{h}_{\mathrm{t}+1}, \mathrm{~b}_{\mathrm{t}+1}\right\}
\end{gathered}
$$

subject to

$$
c_{t}+q_{t} x_{t}+s_{t}+f 1\left\{x_{t} \neq 0\right\}=y_{t}+i_{t} b_{t}
$$




$$
\begin{gathered}
b_{t+1}-b_{t}=s_{t}-\pi b_{t} \\
h_{t+1}-h_{t}=x_{t} \\
b_{t+1} \geq-m q_{t} h_{t+1}
\end{gathered}
$$

Besides the credit constraint, which was discussed above, the optimization includes 3 additional constraints. One is the usual budget constraint equating total real income to total expenditures. The second constraint says that real saving should be equal to the difference between bondholding for the next period and the current bondholding net of inflation. The third says that each period's investment into housing should be equal to the difference between the next period's housing stock and the current housing stock.

One can substitute (3) and (4) into (2) to simplify the maximization and obtain the following constraints:

$$
\begin{gathered}
\mathrm{c}_{\mathrm{t}}=\mathrm{y}_{\mathrm{t}}+\mathrm{i}_{\mathrm{t}} \mathrm{b}_{\mathrm{t}}-\mathrm{q}_{\mathrm{t}}\left(\mathrm{h}_{\mathrm{t}+1}-\mathrm{h}_{\mathrm{t}}\right)-\left(\mathrm{b}_{\mathrm{t}+1}-(1-\pi) \mathrm{b}_{\mathrm{t}}\right)-\mathrm{fl}\left\{\mathrm{x}_{\mathrm{t}} \neq 0\right\} \\
b_{t+1} \geq-m q_{t} h_{t+1}
\end{gathered}
$$

The maximization of (1) subject to (6) and (7) gives the following F.O.C. and Envelope conditions:

$$
\begin{gathered}
\frac{\partial u\left(c_{t}, h_{t}\right)}{\partial c_{t}}=\lambda_{t} \\
-q_{t} \lambda_{t}+\beta \frac{\partial V\left(h_{t+1} b_{t+1}, q_{t+1}, y_{t+1}\right)}{\partial h_{t+1}}+v_{t} m q_{t}=0 \\
-\lambda_{t}+v_{t}+\beta \frac{\partial V\left(h_{t+1}, b_{t+1}, q_{t+1}, y_{t+1}\right)}{\partial b_{t+1}}=0 \\
\frac{\partial V\left(h_{t}, b_{t}, q_{t}, y_{t}\right)}{\partial h_{t}}=\frac{\partial u\left(c_{t}, h_{t}\right)}{\partial h_{t}}+\lambda_{t} q_{t} \\
\frac{\partial V\left(h_{t}, b_{t}, q_{t}, y_{t}\right)}{\partial b_{t}}=\lambda_{t}\left(i_{t}+(1-\pi)\right)
\end{gathered}
$$

where $v$ is the multiplier for the credit constraint and $\lambda$ is the multiplier for the budget constraint. From equation (10) it is possible to determine under what condition the multiplier of credit constraint $v t$ is positive meaning that constraint is binding. Substituting equation (8) and equation (12) into condition (10) and rearranging yields the following formula for $v_{t}$ :

$$
v_{\mathrm{t}}=\frac{\partial u\left(c_{t}, h_{t}\right)}{\partial c_{t}}-\beta \frac{\partial u\left(c_{t+1}, h_{t+1}\right)}{\partial c_{t+1}}\left(\mathrm{i}_{\mathrm{t}+1}+1-\pi\right)
$$

This last equation implies that constraint is binding if the following holds: 


$$
\frac{\frac{\partial u\left(c_{t}, h_{t}\right)}{\partial c_{t}}}{\beta \frac{\partial u\left(c_{t+1}, h_{t+1}\right)}{\partial c_{t+1}}}>\mathrm{i}_{\mathrm{t}+1}+1-\pi
$$

Thus credit constraint is binding if intertemporal marginal rate of substitution between consumption today and consumption tomorrow is higher than gross real interest rate.

Now the dynamic welfare adjustment first defined in Bajari et al. (2005) should be derived for an economy subject to credit constraints. In this paper analysis is focused on the case with binding credit constraint (condition (13) guarantees that it is binding and values of parameters are set so that this condition is satisfied) and it is used with equality. Let us define welfare adjustment as the compensation in the form of income necessary to keep a household indifferent between the new and old prices or in other words to keep value function constant holding fixed hall other factors except income. In essence this means that welfare adjustment is the change in income necessary to keep lifetime utility unchanged. This change in income is converted into utility terms by multiplying it by the marginal utility of wealth which is equal to the Lagrange multiplier of the budget constraint.

The change in the value function due to a change in housing price can be defined as:

$$
\Delta V_{i}=\frac{\partial V\left(h_{t}, b_{t}, q_{t}, y_{t}\right)}{\partial q_{t}} \Delta q_{t}
$$

After the household is compensated for the change in lifetime utility due to change in housing price the final change in value function is given by:

$$
\Delta V_{T}=\frac{\partial V\left(h_{t}, b_{t}, q_{t}, y_{t}\right)}{\partial q_{t}} \Delta q+\frac{\partial V\left(h_{t}, b_{t}, q_{t}, y_{t}\right)}{\partial y_{t}} \Delta y
$$

Following Bajari (2005) an envelope theorem and first order approximation is applied to study the household's behaviour at the optimal point where the value function is time invariant. Taking derivatives yields:

$$
\begin{gathered}
\frac{\partial V\left(h_{t}, b_{t}, q_{t}, y_{t}\right)}{\partial y_{t}}=\frac{\partial u\left(c_{t}, h_{t}\right)}{\partial c_{t}} \\
\frac{\partial V\left(h_{t}, b_{t}, q_{t}, y_{t}\right)}{\partial q_{t}}=\frac{\partial u\left(c_{t}, h_{t}\right)}{\partial c_{t}} \cdot \frac{\partial c_{t}}{\partial q_{t}}=\frac{\partial u\left(c_{t}, h_{t}\right)}{\partial c_{t}}\left(-x_{t}\right)+\left(\frac{\partial u\left(c_{t}, h_{t}\right)}{\partial c_{t}} \mathrm{mh}_{\mathrm{t}+1}-\beta \frac{\partial u\left(c_{t+1}, h_{t+1}\right)}{\partial c_{t+1}}\left(\mathrm{i}_{\mathrm{t}+1}+1-\pi\right) \mathrm{mh}_{\mathrm{t}+1}\right)
\end{gathered}
$$

1 The analysis in this paper is covering the period from 1995 to 2006. For this period the assumption of credit constraint remaining constantly binding can be justified by the large increase in mortgage refinancing activity in the US. In particular the refinancing index, which is published by Mortgage Bankers Association of America and changes in which represent percent changes in mortgage refinancing applications compared with the previous month, increased from 1.5 in 1995 to around 12 in 2006. One of the crucial reasons behind this increase was the desire of the consumers to extract housing equity built-up as a result of housing price appreciation. This refinancing makes nonbinding credit constraint binding again. 
Thus in this economy, the effect of a price change on value function consists of two effects, a direct one and an indirect one. When housing price appreciates, there is a decrease in consumption due to more expensive investment into housing. This is the direct effect reflected in the first term in equation (16). On the other hand, due to the increase in price, the housing equity increases and borrowing constraint relaxes. This allows households to increase borrowing and, consequently, current consumption. This benefit net of the cost of repaying the additional borrowing in the next period is presented in parentheses in equation (16). This is the indirect effect.

Equating $\Delta V$ to zero gives and expressing $\Delta y$ from the resulting equation yields the following formula for the individual welfare adjustment in this model:

$$
\begin{aligned}
& \Delta y_{t}=x_{t} \Delta q_{t}-m h_{t+1} \Delta q_{t}+\frac{\beta \frac{\partial u\left(c_{t+1}, h_{t+1}\right)}{\partial c_{t+1}}}{\frac{\partial u\left(c_{t}, h_{t}\right)}{\partial c_{t}}}\left(\mathrm{i}_{\mathrm{t}+1}+1-\pi\right) \mathrm{mh}_{\mathrm{t}+1} \Delta q_{t}= \\
& =x_{t} \Delta q_{t}-\left(m h_{t+1} \Delta q_{t}-\frac{\left(\mathrm{i}_{\mathrm{t}+1}+1-\pi\right)}{\frac{\partial u\left(c_{t}, h_{t}\right)}{\partial c_{t}}} \mathrm{mh}_{\mathrm{t}+1} \Delta q_{t}\right)
\end{aligned}
$$

Taking into account equation (13) it can be seen that under the binding credit constraints the term in parenthesis in the last equation is positive. Using the utility function of the form $u(c, h)=\frac{\left(\mathrm{c}^{1-\omega} h^{\omega}\right)^{1-\gamma}}{1-\gamma}$ based on Li and Yao (2005), the welfare adjustment can be presented in the following form:

$$
\Delta y_{t}=x_{t} \Delta q_{t}-\left(m h_{t+1} \Delta q_{t}+\frac{\beta\left(\mathrm{i}_{\mathrm{t}+1}+1-\pi\right)(1+\mu)^{\omega-\omega \gamma}}{(1+\sigma)^{\omega-\omega \omega \gamma+\gamma}} m h_{t+1} \Delta q_{t}\right),
$$

where $\mu$ stands for housing stock growth rate and $\sigma$ stands for composite good consumption growth rate.

Let us also discuss the result in case of using Kiyotaki-Moore constraint. This constraint limits the borrowing so that gross repayment next period does not exceed a fraction of next period's expected monetary value of the collateral asset. In terms of the present model it has the form $\left(1+\mathrm{i}_{\mathrm{t}+1}\right) b_{t+1} \geq m E_{t} q_{t+1} h_{t+1}$. The crucial difference between margin clause and this constraint is that the next period's price rather than this period's price enters into the credit constraint. If the housing price next period is not affected by the change in current price, the credit constraint will not be relaxed and consequently change in aggregate welfare will still be zero as in Bajari et al. 
(2005). However, several empirical papers have demonstrated that housing prices follow either random walk or AR (1) with high persistence. Using AR (1) assumption and applying the same procedure to the model with a Kiyotaki-Moore constraint, the following formula for the individual welfare adjustment can be derived:

$$
\begin{gathered}
\Delta y_{t}=x_{t} \Delta q_{t}-\frac{\rho m h_{t+1} \Delta q_{t}}{1+\mathrm{i}_{\mathrm{t}+1}}+\frac{\left(\mathrm{i}_{\mathrm{t}+1}+1-\pi\right) \rho m h_{t+1} \Delta q_{t}}{\frac{\partial u\left(c_{t}, h_{t}\right)}{\partial c_{t}}} \\
\frac{\frac{\partial u\left(c_{t+1}, h_{t+1}\right)}{\partial c_{t+1}}}{\left(1+\mathrm{i}_{\mathrm{t}+1}\right)}
\end{gathered}
$$

Here the positive effect on consumption due to relaxation of credit constraint is discounted by the gross interest rate since it can be realized only next period.

\subsection{Interpretation and Quantification of Welfare Adjustment}

This section interprets and quantifies the final result. For convenience, here we restate the formula for individual welfare adjustment:

$$
\Delta y_{j, t}=x_{j, t} \Delta q_{t}-\left(m h_{j, t+1} \Delta q_{t}+\frac{\beta\left(\mathrm{i}_{t+1}+1-\pi\right)(1+\mu)^{\omega-\omega \gamma}}{(1+\sigma)^{\omega-\omega \gamma+\gamma}} m h_{j, t+1} \Delta q_{t}\right) \text { for household } j
$$

Comparing the result in (16) to that of Bajari et al. (2005), two crucial differences can be noted. First, as it was shown above, the term in parenthesis in equation (16) is positive which implies that for all households in the model economy the potential welfare loss is lower (welfare gain is higher) than in the benchmark paper since there is an additional beneficial effect of housing price appreciation on consumption. This effect comes in the form of relaxation of credit constraints which gives a better opportunity to smooth consumption. Second, homeowners do get a certain benefit from housing price appreciation even without participating in housing transactions (when $x_{j, t}=0$ ), which is quite consistent with reality. For instance, older homeowners can leave larger bequests or invest more in retirement accounts even without selling their house. Younger homeowners can shift their investment to risky assets or increase consumption.

The aggregate welfare adjustment is equal to the sum of individual adjustments as defined by (16). Using the assumption of investment only into existing housing stock and summing up, the first term of the expression vanishes. The term in parenthesis in equation (16) does not sum up to zero since all the households are subject to binding credit constraints implying that all the households are net borrowers. Here it is assumed that funds for borrowing are supplied from external sources. This appears to be a reasonable assumption for US economy. In the discussed period in the US economy, borrowing was largely financed by means of increasing external debt. In particular, from 1995 to 2003 total US external debt rose from 26 trillion dollars to 45 trillion dollars (Federal Reserve, US Treasury data). While the US government debt remained almost unchanged during this period, the US financial sector external debt increased by around $70 \%$ and business external debt increased by around 30\% (Federal Reserve, US Treasury data). As a result the following expression is left for the aggregate welfare adjustment: 


$$
\begin{aligned}
& W_{t}=-\sum_{j}\left(m h_{j, t+1} \Delta q_{t}-\frac{\beta\left(\mathrm{i}_{\mathrm{t}+1}+1-\pi\right)(1+\mu)^{\omega-\omega \gamma}}{(1+\sigma)^{\omega-\omega-\partial \gamma+\gamma}} m h_{j, t+1} \Delta q_{t}\right)= \\
& =-\left(m \sum_{j} h_{j, t+1} \Delta q_{t}-\frac{\beta\left(\mathrm{i}_{\mathrm{t}+1}+1-\pi\right)(1+\mu)^{\omega-\omega \gamma}}{(1+\sigma)^{\omega-\omega \gamma+\gamma}} m \sum_{j} h_{j, t+1} \Delta q_{t}\right)
\end{aligned}
$$

Since it was shown that the term in parenthesis in equation (17) is positive under binding credit constraint, the total sum in equation (17) is negative. Thus, the aggregate welfare adjustment in this economy with exogenous housing prices and credit-constrained households is negative, implying that in aggregate less income is necessary to keep lifetime utility constant. That is, housing price appreciation in an economy subject to binding credit constraints actually implies an improvement in aggregate welfare. Everybody in the economy who possesses any housing stock is made better off due to the relaxation of binding credit constraints. The finding is consistent with the observation that in certain years characterized by housing price appreciation developed countries experienced consumption growth or even a consumption boom (Campbell and Cocco, 2004).

It is possible to quantify the result in (17) and compare it to the result of Bajari et al. (2005). The composite good consumption growth rate is approximated by the non-durable consumption growth rate taken from Bureau of Economic Analysis NIPA tables. The residential housing stock growth rate is taken from the Bureau of Economic Analysis Fixed Asset Tables. Inflation and risk-free interest rate are taken from IMF International Financial Statistics. Also, it is assumed that $\mathrm{m}=0.8$ (standard LTV for conventional mortgages in US), $\gamma=2$ (based on $\mathrm{Li}$ and Yao, 2005), $\omega=0.5$ (based on $\mathrm{Li}$ and Yao, 2005), and $\beta=0.98$.

The term $\sum_{j} h_{j, t+1} \Delta q_{t}$ can be interpreted as the change in the market value of the total housing stock, or in other words as the change in the aggregate nominal housing wealth. The data on aggregate nominal housing wealth in the US can be obtained from several studies (such as Case, Quigley and Shiller, 2001; Nothaft, 2004; etc) and also from American Housing Survey for the years after 2003. However, when using it to quantify the result of this model, it is important to take into account three observations. Firstly, the model does not have the explicit choice of renting the house. Consequently, only the change in the value of owner-occupied housing stock should be considered. Secondly, the effect of relaxing borrowing constraints reflected in (17) should in reality be experienced only by credit-constrained households who take a mortgage when purchasing the house. Finally, due to considering the case of binding credit constraints, this result is true for the households having mortgages with a maximum LTV (or close to it). Based on these considerations, the yearly change in the nominal housing wealth in US is multiplied by the share of owner-occupied housing in the total housing stock, by the share of mortgage-financed owner-occupied housing in the total owner occupied housing stock and also by the share of mortgages with maximum LTV in the total number of mortgages. The resulting numbers are then divided by the total number of households in the US economy (taken from Current Population Report of US Department of Commerce) to obtain per household change in aggregate welfare (in 2003 dollars) in the model with credit-constrained households. The results are displayed in Figure 1. The figure displays the absolute value of welfare change in (19) so the numbers are positive. 
The obtained results contrast sharply with those of Bajari et al. (2005), who found no effects of housing price appreciation on aggregate welfare in case of investing into existing housing stock. It turns out that when accounting for binding credit constraints, the housing price appreciation which occurred in the US between 1995 and 2006 improved aggregate welfare on average by around 907 dollars per household a year or around 12,880 dollars per household in total.

Figure 1

Per Household Improvement in Aggregate Welfare (2003, USD)

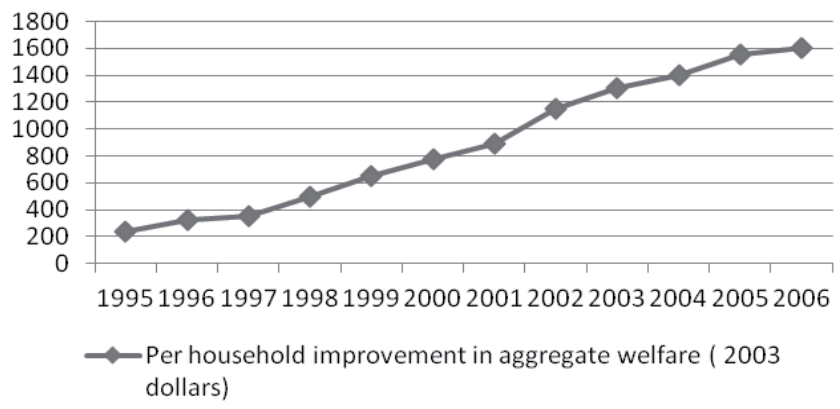

Source: Own calculations based on Historical Income Tables, US Census Bureau.

\section{Model with Endogenous Housing Prices ${ }^{2}$}

\subsection{Households}

The basic assumptions about the household sector in this model are analogous to the assumptions in Section 2. The crucial difference is that the housing price is determined endogenously. To be more realistic this version takes into account physical depreciation of housing assumed to occur depreciates with constant rate $\delta$.

The household's problem in the economy with endogenous housing price and credit constraints can be formulated as follows:

$$
\begin{gathered}
V\left(h_{t}, b_{t}, y_{t}\right)=\max \left\{u\left(c_{t}, h_{t}\right)+\beta V\left(h_{t+1}, b_{t+1}, y_{t+1}\right)\right\} \\
\left\{\mathrm{c}_{\mathrm{t}}, \mathrm{h}_{\mathrm{t}+1}, \mathrm{~b}_{\mathrm{t}+1}\right\}
\end{gathered}
$$

s.t.

$$
\begin{gathered}
c_{t}+q_{t} \cdot x_{d, t}+s_{t}+f 1\left\{x_{t} \neq 0\right\}=y_{t}+i_{t} \cdot b_{t} \\
b_{t+1}-b_{t}=s_{t}-\pi \cdot b_{t} \\
h_{t+1}-h_{t}=x_{d, t}-\delta \cdot h_{t} \\
b_{t+1} \geq-m q_{t} h_{t+1}
\end{gathered}
$$

2 Most of the derivations of steady state conditions and equilibrium conditions can be obtained from the authors upon request. 
where subscript $d$ denotes a variable belonging to the demand side of the housing market. The Euler equations for this model are given by:

$$
\begin{gathered}
v_{t}=\frac{\partial u\left(c_{t}, h_{t}\right)}{\partial c_{t}}-\beta \cdot \frac{\partial u\left(c_{t+1}, h_{t+1}\right)}{\partial c_{t+1}} \cdot\left(i_{t+1}+(1-\pi)\right) \\
q_{t} \cdot \frac{\partial u\left(c_{t}, h_{t}\right)}{\partial c_{t}}=\beta \cdot \frac{\partial u\left(c_{t+1}, h_{t+1}\right)}{\partial h_{t+1}}+ \\
+\beta \cdot \frac{\partial u\left(c_{t+1}, h_{t+1}\right)}{\partial c_{t+1}} \cdot q_{t+1} \cdot(1-\delta)+m q_{t}\left(\frac{\partial u\left(c_{t}, h_{t}\right)}{\partial c_{t}}-\beta \cdot \frac{\partial u\left(c_{t+1}, h_{t+1}\right)}{\partial c_{t+1}} \cdot\left(i_{t+1}+(1-\pi)\right)\right)
\end{gathered}
$$

In the unconstrained version of the model, households are not subject to a credit constraint. Therefore, it is absent from their optimization problem. The rest of the problem is the same. Euler equations for this model are given by:

$$
\begin{gathered}
\frac{\partial u\left(c_{t}, h_{t}\right)}{\partial c_{t}}=\beta \cdot \frac{\partial u\left(c_{t+1}, h_{t+1}\right)}{\partial c_{t+1}} \cdot\left(i_{t+1}+(1-\pi)\right) \\
q_{t} \cdot \frac{\partial u\left(c_{t}, h_{t}\right)}{\partial c_{t}}=\beta \cdot \frac{\partial u\left(c_{t+1}, h_{t+1}\right)}{\partial h_{t+1}}+\beta \cdot \frac{\partial u\left(c_{t+1}, h_{t+1}\right)}{\partial c_{t+1}} \cdot q_{t+1} \cdot(1-\delta)
\end{gathered}
$$

\subsection{Construction Firms}

Supply side of the market is identical for both credit constrained and unconstrained versions of the model economy. In modelling the production of new housing we rely primarily on Amin and Capozza (1993). Let us assume that there is a perfectly competitive sector of construction firms that supply units to the housing market. The representative firm acts to maximize its profits taking the housing price as given. It has a production function given by $H_{s t}=G\left(K_{t}, L_{t}\right)=K_{t}^{\alpha} \cdot L_{t}^{1-\alpha}$, where $K_{t}$ is the amount of capital used, $L_{t}$ is the amount land used and $\alpha<1$. We assume that firms face constant returns to scale technology which implies a linear cost function with constant marginal cost, denoted by $d$. Output per unit of land is given by $h_{s, t}=g\left(k_{t}\right)=H_{s, t} / L=(K / L)^{\alpha}=\left(k_{t}\right)^{\alpha}$. Under these assumptions the total cost of production is given by. Construction firms need to obtain a permit from the zoning authority, a process that involves costs. The cost of each permit is given by $\mathrm{n}$, which includes both cash expenditures needed to obtain the building permit as well as the cost of time necessary to obtain the building permit (in monetary terms). In real US economy regulation cost can vary either according to the value of the building project or according to the square footage of the constructed housing unit. Both the demand as well as the supply side of the model economy is calibrated in terms of average housing unit, which will be defined later. Consequently, the dollar value of the building permit cost is set according to the square footage of this typical unit. Under such calibration, one building permit is necessary to build one unit of output, that is, one average housing unit. This assumption is further justified by the fact that the entire US Census Bureau data on building permits is reported in terms of new privately owned housing units authorized in permit-issuing places, rather than in terms of number of obtained building permits per se. 
With these assumptions, the maximization problem of a construction firm is given by:

$$
\begin{array}{r}
\operatorname{Max}_{k_{t}} q_{t} \cdot h_{s, t}-d \cdot k_{t}-h_{s, t} \cdot n \\
\text { s.t. } \quad x_{s, t}=\left(k_{t}\right)^{\alpha}
\end{array}
$$

From the maximization, one can get the optimal amount of input used by construction firm

$$
k_{t}=\left(\frac{\alpha \cdot q_{t}-\alpha \cdot n}{d}\right)^{(1 /(1-\alpha))}
$$

This gives the optimal amount of capital to land ratio chosen by the representative firm. Substituting back into the production function yields the amount of housing produced per unit of land:

$$
x_{s t}=g\left(k_{t}\right)=\left(\frac{\alpha \cdot q_{t}-\alpha \cdot n}{d}\right)^{(\alpha /(1-\alpha))}
$$

Moreover, since it is a representative firm and in equilibrium all the firms will act in the same way, multiplication of it by the aggregate stock of land will give the aggregate supply of new housing in equilibrium.

\subsection{Definition of Equilibrium}

Let's define aggregate supply of land as $\bar{L}$. It is reasonable to assume that supply of land is inelastic, that is the aggregate quantity of land is fixed in the short run. Let's assume that there is exogenous given output of composite consumption good which is given by $Y_{t}$. The supply side of the consumption good market is not modelled explicitly, since the analysis is focused on the housing market. Also, the model with credit constraints is analyzed in the situation where credit constraint is binding. This implies that all households are net borrowers, with the amount of borrowing determined endogenously depending on the amount of housing consumption chosen. The equilibrium in credit market is not modelled here since the analysis is not focused on the behaviour of the interest rate. It is assumed instead that there is an exogenously given supply of borrowing funds $B_{t}$ which is coming from abroad (evidence for this was provided above).

The equilibrium consists of prices $\left\{q_{t}\right\}_{t=0}^{\infty}$ interestrates $i_{t}$, allocations $\left\{c_{t}, h_{t+1}, b_{t+1}\right\}_{t=0}^{\infty}$ by households and profit maximizing input $\left\{k_{t}\right\}_{t=0}^{\infty}$ by firms such that:

1) given prices households solve their optimization problem (conditions (18)-(21)) and firms maximize their profits (condition (22))

2) markets clear

i) $x_{d, t}=g\left(k_{T}\right) \cdot \bar{L} \quad$ (housing market)

ii) $c_{t}=Y_{t}$ (consumption good market)

iii) $b_{t+1}=B_{t}$ (for credit constrained economy bond market)

For unconstrained economy definition is the same except of the bond market clearing condition, given by the following:

$$
b_{t+1}=0 \text {. }
$$


The last condition comes from the fact that in a standard unconstrained representative agent asset pricing model in equilibrium lending should compensate borrowing.

\section{Characterization of the Welfare Adjustment: Supply Side Shocks}

\subsection{Welfare Adjustment Derivation}

In this section the formula for welfare adjustment due to an endogenous housing price appreciation for an economy in a steady state is derived. The full derivation of steady state for both credit-constrained and unconstrained versions of the model is given in the appendix. Based on Li and Yao (2005) modified Cobb-Douglas utility function of the $u(c, h)=\frac{\left(\mathrm{c}^{1-\omega} h^{\omega}\right)^{1-\gamma}}{1-\gamma}$ is used. Suppose now that the economy is in steady state when regulation costs reflected in $n$ increase. It is evident from (22) that this shifts down the profit-maximizing level of input and reduces the profit-maximizing output of the competitive firms per unit of land used. Consequently, the aggregate supply of new residential housing decreases and housing price appreciates (the expression for the response of housing price to the change in building permit costs is derived in the appendix). Similar to Section 2, the welfare adjustment is defined as the change in income necessary to keep lifetime utility constant when $\mathrm{n}$ changes. The change in value function resulting from the change in $\mathrm{n}$ is given by:

$$
\Delta V=\frac{\partial V\left(h^{s s}, b^{s s}, y^{s s}\right)}{\partial n} \cdot \Delta n+\frac{\partial V\left(h^{s s}, b^{s s}, y^{s s}\right)}{\partial y} \cdot \Delta y
$$

where superscript ss denotes steady state values.

Using utility form defined above, calculating the corresponding derivatives, substituting them to the last equation, equating $\Delta \mathrm{V}$ to zero and expressing $\Delta \mathrm{y}$ from the resulting equation yields the following formulas for the welfare adjustments:

$$
\begin{array}{rr}
\Delta y=\Delta n \cdot \omega \cdot \frac{B}{\beta(1-\omega) D}\left(\frac{\alpha}{q^{s s}-n \cdot(1-\alpha)}\right)\left(\frac{y^{s s}-f 1\left\{x^{s s} \neq 0\right\}}{A}\right) & \text { for credit constrained } \\
\text { model (24) }
\end{array}
$$

where $\mathrm{A}, \mathrm{B}$ and $\mathrm{D}$ are constants.

\subsection{Interpretation and Comparison}

In this section the welfare adjustments in the models with endogenous housing prices driven by supply-side shocks are signed and compared.

The result in an economy with an endogenous housing price but without credit constraints is given by the following:

$$
\Delta y=\Delta n \cdot \omega \cdot\left(i^{s s}+\delta-\pi\right) \cdot\left(\frac{y^{s s}-f 1\left\{x^{s s} \neq 0\right\}}{A}\right) \cdot\left(\frac{\alpha}{q^{s s}-n \cdot(1-\alpha)}\right),
$$

where $A=(1-\omega) \cdot i^{s s}+\omega \cdot \pi+\delta-\pi$ and $\alpha<1$. 
Based on International Financial Statistics published by IMF we assume $\pi=0.02$ and $i=0.047$ (these are contemporary values for inflation and nominal interest rate on long term government bonds in the US in 2006). Based on Margolis (1982) and Malpezzi, Ozanne, and Thibodeau (1987) and the fact that in the end of 1980s and beginning of 1990 s the Congress raised depreciation period for housing in the US to 27.5 years, which implies a yearly depreciation rate of around $3.5 \%$, housing depreciation rate is set at $\delta=0.025$. This is broadly in accordance with what is also suggested by McFarlane (2001). Based on International Financial Statistics published by IMF we assume $\pi=0.02$ and $i=0.042$ (these are contemporary values for inflation and nominal interest rate on long term government bonds in the US). Using the assumed values and setting $\omega=0.56$ (justification for this is given later in the section) gives $A=0.0338$, which implies that 5 -th term in the product in (26) is positive. Also the 4-th term is positive. The 3-rd term is positive since it reflects the effect of change in regulation costs on the housing prices, which must be strictly positive. Change in $n$ is positive by assumption. Consequently the individual welfare adjustment in this model is positive. Thus, in an economy with endogenous housing prices where households are not credit-constrained, the housing price appreciation driven by negative supply side shock leads to a welfare $\operatorname{loss}^{3}$.

In a model with both credit constraints and endogenous housing prices, the welfare adjustment is given by:

$$
\Delta y=\Delta n \cdot \omega \cdot \frac{\alpha}{q^{s s}-n \cdot(1-\alpha)} \cdot\left(\frac{B}{\beta} \cdot \frac{1}{1-\omega} \cdot\left(\frac{y^{s s}-f 1\left\{x^{s s} \neq 0\right\}}{D}\right)\right),
$$

where $B=1-\beta \cdot(1-\delta)-m\left(1-\beta \cdot\left(i^{s s}+1-\pi\right)\right)$ and $D=\frac{1-\omega}{\omega \cdot \beta} \cdot B-m \cdot \pi+i^{s s} \cdot m+\delta$

Under assumed values of parameters constants B and D are positive. Consequently in this economy also the welfare adjustment is positive implying that in case of endogenous housing price appreciation driven by negative supply shock and Cobb-Douglas preferences agents experience welfare loss both in the case of presence of credit constraints as well as without them.

One can compare the last two formulas for welfare adjustments to establish whether credit constraints alleviate or exacerbate the welfare loss from a negative supply shock. For simplicity let's abstract from fixed transaction costs; that is assuming that $f 1\left\{x^{s s} \neq 0\right\}=0$. Also, to make a fair comparison, let's ignore the possible difference between income of credit-constrained and unconstrained households and assume the same income for both economies. Examining (26) and (27), it is evident that for comparing those two results one should compare the terms $\frac{i^{s s}+\delta-\pi}{A}$ and $\frac{B}{\beta(1-\omega) D}$. In both economies we set $\pi=0.02$. For credit constrained economy we set $i^{s s, c}=0,059$, which was the level of the level of the average effective interest

3 According to our definition positive $\Delta y$ means welfare loss since people need more income to keep them indifferent between old and new prices. 
rate on mortgages in US in 2006 (obtained from Monthly Interest Rate Survey of Federal Housing Finance Board). Also, it is important to recall that here an economy with binding credit constraints is considered. In this case the Lagrange multiplier of the credit constraint is positive, that is $v^{s s}>0$. Mathematically, discount factor for the economy with binding credit constraint is given by $\beta^{\prime}=\frac{1-v^{s s} / \frac{\partial u\left(c^{s s}, h^{s s}\right)}{\partial c^{s s}}}{i^{s s}+(1-\pi)}$ while the discount factor for the economy without credit constraints is given by $\beta=\frac{1}{i^{s s}+(1-\pi)}$. Looking at the last two expressions and taking into account that $v^{s s}>0$ and interest rate is higher in the economy with binding credit constraints it is evident that the discount factor in this economy should be lower than the discount factor in the unconstrained economy. Thus for the economy with binding credit constraints we set $\beta=0.96$, which is somewhat lower than conventional $0.98-0.99$. Using all these values sensitivity analysis is performed by computing both terms mentioned above for values of preference parameter $\omega$ from 0.1 to 0.9 . The results are presented in Table 2 .

Table 2

Comparison of Welfare Adjustments for Different Values of $\omega$

\begin{tabular}{|l|c|c|}
\hline$\omega$ & Unconstrained & Constrained \\
\hline & $\frac{i^{s s}+\delta-\pi}{A}$ & $B$ \\
\hline $\mathbf{0 . 1}$ & 1.046781 & 0.121252 \\
\hline $\mathbf{0 . 2}$ & 1.098154 & 0.274385 \\
\hline $\mathbf{0 . 3}$ & 1.154829 & 0.473092 \\
\hline $\mathbf{0 . 4}$ & 1.217672 & 0.74190 \\
\hline $\mathbf{0 . 5}$ & 1.287749 & 1.323798 \\
\hline $\mathbf{0 . 6}$ & 1.366385 & 1.685037 \\
\hline $\mathbf{0 . 7}$ & 1.455248 & 2.636675 \\
\hline $\mathbf{0 . 8}$ & 1.556474 & 4.546914 \\
\hline $\mathbf{0 . 9}$ & 1.672835 & 8.291815 \\
\hline
\end{tabular}

Source: Own calculations.

The table demonstrates that welfare adjustment resulting from housing price appreciation due to increase in regulation costs is lower in credit constrained economy than in unconstrained economy for all $\omega \leq 0.5$ but it is higher in the constrained economy than in the unconstrained economy for all $\omega>0.5$. Thus the relationship between the welfare changes in credit constrained and unconstrained economy depends on the relative weight of housing in the agent's utility function. When $\omega>0.5$, the housing consumption is more important to the households than consumption of composite good. Since credit constrained households intuitively have lower housing stock than 
unconstrained ones the marginal utility of housing for them is higher. Consequently when housing consumption has relatively high weight in the utility function credit constrained households loose more from a decrease in their steady state housing stock which has higher marginal utility for them than credit unconstrained households.

It is possible to calculate $\omega$ using shares of housing and non-durable consumption in average annual expenditures in the US economy. According to the Consumer Expenditures Survey published by Bureau of Labor Statistics the share of housing in the expenditures in 2004 was equal to $32.1 \%$ and the share of non-durable consumption (aggregated from separate components given in the Consumption Expenditure Survey) was equal to $49 \%$. On the other hand in our model the dollar value of one period expenditures on composite good (non-durable consumption) is given by $c^{s s}$ (since the price of consumption is normalized at 1) and the dollar value of one period expenditures on housing is given by $\delta q^{s s} h^{s s}$ (since during one period households consume value of the depreciated housing stock). Looking at the steady state allocations in the appendix it is easy to see that in both credit-constrained and unconstrained versions of the economy the ratio $\frac{c^{s s}}{\delta q^{s s} h^{s s}}$ is a function of $\omega$ only and the other already calibrated parameters. On the other hand mathematically it is true that:

$$
\frac{c^{s s}}{\delta q^{s s} h^{s s}}=\frac{\frac{c^{s s}}{\text { expenditures }}}{\frac{\delta q^{s s} h^{s s}}{\text { expenditures }}}=\frac{0.49}{0.321}
$$

Thus, $\omega$ can be calculated from this equation. For defining the plausible range of values for $\omega$ at first all the households in the actual economy are treated as unconstrained and $\omega$ is calculated from the above equation using steady state allocations of the unconstrained model. Then all the households are treated as credit-constrained and $\omega$ is calculated using allocations from the credit-constrained model.

The unconstrained model gives:

$$
\frac{c^{s s}}{\delta q^{s s} h^{s s}}=\frac{(1-\omega)\left(i^{s s}+\delta-\pi\right)}{\omega \delta}=\frac{0,49}{0,321}, \quad \text { from which } \omega=0,56
$$

The constrained model gives:

$$
\frac{c^{s s}}{\delta q^{s s} h^{s s}}=\frac{B(1-\omega)\left(i^{s s}+\delta-\pi\right)}{\omega \beta \delta}=\frac{0,49}{0,321}, \quad \text { from which } \omega=0,64
$$

Since there are both types of households in the actual economy, the true value of $\omega$ should be between 0.56 and 0.64 . In case of $\omega=0.56$ the adjustment in constrained model is only marginally higher than that in the unconstrained economy, while in the case $\omega=0.64$ credit-constrained households clearly loose more from negative supply shock. 


\section{Characterization of the Welfare Adjustment: Supply Side Shocks}

\subsection{Shifts in Income as the Reason of Housing Price Appreciation}

In general, the changes in income constitute the most natural demand-side shock in any market including the housing market. Consequently, when searching for demandside shocks affecting housing prices we first look at the dynamics of income in the US during the years of housing price appreciation. Annual figures for median household income in the US, obtained from the Current Population Survey of US Census Bureau are presented in Figure 2 together with constant-quality housing price index.

Figure 2

Joint Household Income and Constant Quality Housing Price Index in US

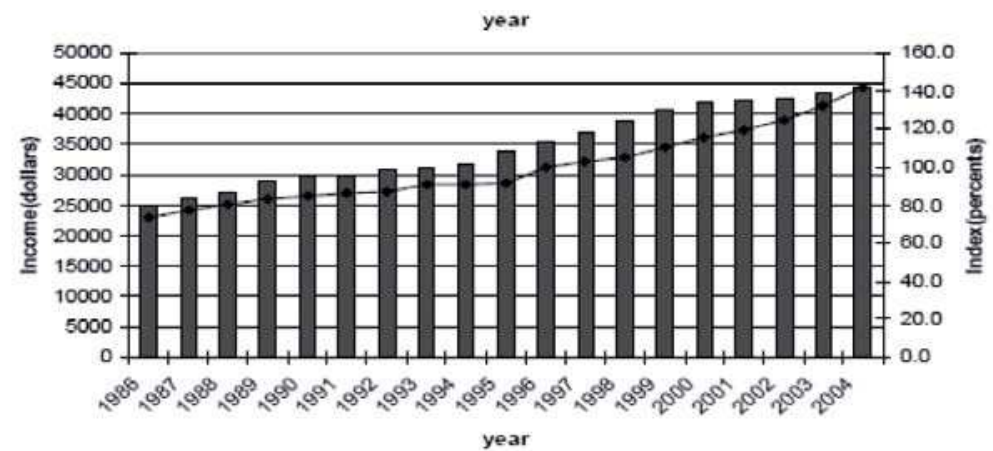

$\longrightarrow$ Median household income in US in 2006 dollars
$\rightarrow$ Constant-quality housing price index(1996=100\%)

Source: Own calculations Historical Income Tables, US Census Bureau.

The graph clearly shows that years of substantial housing price appreciation were characterized by a considerable upward shift in the median household income which, after staying nearly constant in the first half of the $90^{\circ} \mathrm{s}$, began to grow rapidly in the second half. Calculating the growth rate of income from US Census Bureau data indicates that in 1988-1994 median household income increased by only $17.7 \%$ while in 1995-2001 it grew by $24.5 \%$. Empirical evidence would thus suggest that changes in income were an important demand-side driver of housing price appreciation in the last decade.

Let's denote by $\Delta y_{\text {new }}$ the new change in income that is the welfare adjustment and by $\Delta y_{\text {old }}$ the initial change in income that is the shock. The welfare adjustment is derived from the following equation:

$$
\Delta V=\frac{\partial V}{\partial c} \frac{\partial c}{\partial y} \Delta y_{\text {old }}+\frac{\partial V}{\partial h}\left(\frac{\partial h}{\partial y}+\frac{\partial h}{\partial q} \frac{\partial q}{\partial y}\right) \Delta y_{\text {old }}+\frac{\partial V}{\partial y} \Delta y_{\text {new }}=0 .
$$

Equating $\Delta V$ to 0 , using the steady state derived in the appendix, and expressing $\Delta y_{\text {new }}$ from the resulting equation yields the following formulas for the welfare adjustments: 


$$
\Delta y_{\text {new }}=-\frac{(1-\omega)\left(i^{s s}+\delta-\pi\right)}{A} \Delta y_{\text {old }}-\left(i^{s s}+\delta-\pi\right)\left(\frac{\omega}{A}-\frac{\omega\left(y^{s s}-f 1\left\{x_{s s} \neq 0\right\}\right)}{A q^{s s}} \frac{\partial q}{\partial y}\right) \Delta y_{\text {old }}
$$

where

$$
\frac{\partial q}{\partial y}=\frac{J \delta \omega d^{\alpha /(1-\alpha)}}{A q^{s s} \bar{L} \frac{\alpha^{2}}{1-\alpha}\left(\alpha q_{s s}-\alpha n\right)^{\frac{\alpha}{1-\alpha}-1}+A \bar{L}\left(\alpha q^{s s}-\alpha n\right)^{\frac{\alpha}{1-\alpha}}} \succ 0
$$

for unconstrained model

where

$$
\Delta y_{\text {new }}=-\frac{B(1-\omega)}{\omega \beta D} \Delta y_{\text {old }}-\frac{B}{\beta}\left(\frac{1}{D}-\frac{y^{s s}-f 1\left\{x_{s s} \neq 0\right\}}{D \cdot q^{s s}} \frac{\partial q}{\partial y}\right) \Delta y_{\text {old }},
$$

$$
\frac{\partial q}{\partial y}=\frac{J \delta(d)^{\alpha /(1-\alpha)}}{q^{s s} \bar{L} D \frac{\alpha^{2}}{1-\alpha}\left(\alpha q_{s s}-\alpha n\right)^{\frac{\alpha}{1-\alpha}-1}+\bar{L} D\left(\alpha q^{s s}-\alpha n\right)^{\frac{\alpha}{1-\alpha}}}>0
$$

The equation reflecting the response of housing price to changes in income was obtained as in previous cases by applying an implicit function theorem to the housing market clearing condition derived in the appendix. The second terms in the welfare adjustments given above are the final changes in housing stock due to interaction of income and substitution effects.

\subsection{Changes in the Interest Rates as the Reason of Housing Price Appreciation}

A decrease in mortgage interest rates and nominal interest rates on bonds generates an increase in the housing demand for both credit-constrained and unconstrained households. For the credit-constrained households who are net borrowers, a decrease in the mortgage rate implies lower current payments for their mortgages. This increases their disposable income, which in turn means that they can increase housing consumption and/or consumption of the composite good. For the unconstrained households housing and bonds can be viewed as the alternative investment opportunities or assets. Consequently, a decline in the interest rates on bonds makes housing a more attractive investment relative to bonds and the investment is shifted towards housing, thus further raising housing demand.

At this point, one should ask what happened to the nominal interest rates on bonds and mortgage interest rates in the real economy in the 1990s. According to Monthly Interest Rate Survey of the Federal Housing Finance Agency the average effective interest rate on mortgages between 1995 and 2006 decreased from 7.85 to 5.9\%. According to IMF International Financial Statistics long term government bond yields in the US declined from 6.58 to $4.7 \%$. It thus appears quite important to study the welfare implications of housing price appreciation driven by a decrease in interest rates.

The welfare adjustment, defined as in the previous section, is derived from the following equation: 


$$
\Delta V=\frac{\partial V}{\partial c} \frac{\partial c}{\partial i} \Delta i+\frac{\partial V}{\partial h}\left(\frac{\partial h}{\partial i}+\frac{\partial h}{\partial q} \frac{\partial q}{\partial i}\right) \Delta i+\frac{\partial V}{\partial y} \Delta y=0
$$

In the model without credit constraints the final welfare adjustment is given by:

$$
\begin{array}{r}
\Delta y=-\frac{\omega(1-\omega) \delta}{A^{2}}\left(y^{s s}-f 1\left\{x^{s s} \neq 0\right\}\right) \Delta i+\frac{\left(i^{s s}+\delta-\pi\right) \omega(1-\omega)}{A^{2}}\left(y^{s s}-f 1\left\{x^{s s} \neq 0\right\}\right) \Delta i- \\
-\frac{\omega\left(i^{s s}+\delta-\pi\right)}{A}\left(y^{s s}-f 1\left\{x^{s s} \neq 0\right\}\right)\left(\frac{(1-\omega)\left(q^{s s}-n\right)(1-\alpha)}{A\left(q^{s s}-n(1-\alpha)\right)}\right) \Delta i
\end{array}
$$

In the model with credit constraints the final welfare adjustment is given by:

$$
\begin{array}{r}
\Delta y=\frac{1-\omega}{\omega \beta}\left(y^{s s}-f 1\left\{x^{s s} \neq 0\right\}\right)(1-\beta)\left(m-m^{2}\right) \Delta i+\frac{B m}{\beta \omega D^{2}}\left(y^{s s}-f 1\left\{x^{s s} \neq 0\right\}\right) \Delta i+\frac{B m}{\beta \omega D}\left(y^{s s}-.\right. \\
\left.\quad-f 1\left\{x^{s s} \neq 0\right\}\right)\left(\frac{\left(q^{s s}-\chi n\right)(1-\alpha)}{D\left(q^{s s}-\chi n(1-\alpha)\right)}\right) \Delta i
\end{array}
$$

These adjustments are quantified in the next section.

\section{US Economy in 1995-2006: Actual Aggregate Welfare Adjustment}

In the previous sections, welfare adjustments in the model economy were derived for different supply and demand side shocks. In this section the aggregate welfare adjustment resulting from housing price appreciation driven by the combination of shocks observed in US housing market from 1995 to 2006 is computed. According to the US Census Bureau in 2006 1,532,000 single-family housing units with an average area of 2,349 square feet per unit and 310,000 units in buildings with two units or more with an average area of 1,173 square feet per unit were built. Thus, in total 3,962,298,000 square feet of housing were built in the US in 2006. Dividing the total number of square feet produced by the total number of housing units produced yields that the area of an average housing unit was 2,151 square feet. Building permit cost is calculated according to the Craftsman's National Construction Estimator taking into account square footage of the housing unit and US average construction cost per square foot and as a result is set to $n=13160$. Using the report of the National Association of Realtors on the land use, which says that in 2002 (the most recent available estimate) $\bar{L}=658,000$ acres of land were used for residential construction we set. Finally, with this information it is possible to calculate the amount of output per unit of land in the real economy, which is equal to 5,428.41 square feet or 2.79 housing units. With this information in hand the constant marginal cost $\mathrm{d}$ can be calculated. Using (23), which defines the output per unit of land, and solving it for $d$ yields: $x_{s t}=\left(\frac{\alpha q_{t}-\alpha n}{d}\right)^{(\alpha /(1-\alpha))}$. Solving this equation for $d$ we get: 


$$
d=\left(\frac{\left(\alpha q_{t}-\alpha n\right)^{(\alpha /(1-\alpha))}}{x_{s, t}}\right)^{((1-\alpha) / \alpha)}
$$

According to the Monthly Interest Rate Survey of the Federal Housing Finance Board average purchase price of housing in the US in 2006 was 307,100 dollars. Also based on the National Association of Realtors data on capital income and land income shares in the housing construction industry we set $\alpha=0.4$. Finally, according to the calculation above, $x_{s, t}=2.79$. Substituting all parameters into the last equation gives $d=20,586$. It is necessary to specify the structure of population that is number of credit constrained and unconstrained households. Based on 2004 Survey of Consumer Finance by the Federal Reserve System which reports the average net worth of American households according to the age of the household head and testing two possible options for calibration we set $J_{c}=44,784,339$ and $J_{u c}=62,888,650$. Also we set $\omega=0.583$ which is calculated from estimates of $\omega$ for credit constrained and unconstrained co housing the weights corresponding to calibrated number of credit constrained and unconstrained households in the economy. Now let us calculate an implied cumulative welfare adjustment for the actual US economy. According to constant-quality housing price index of the US Census Bureau, housing prices increased by $43.7 \%$ between 1995 and 2006. Also, median household income in the US increased by $41.5 \%$ between 1995 and 2006. Finally, the interest rate on long-term government bonds declined from 6.58 to $4.2 \%$ (by $28.6 \%$ ) during this period while the effective interest rate on mortgages declined from 7.85 to $5.9 \%$ (by $24.8 \%$ ). The only unobservable is the change in the building permit cost or the supply-side shock. The idea is to calculate the elasticity of housing prices with respect to income and interest rates in both a constrained and an unconstrained economy and then to compute the total response housing prices on demand side shocks. The supply-side shock or change in building permit costs can be computed so as to match the residual change in prices in the US economy. To compute the response of housing prices to changes in demand side factors the following formulas are used:

$$
\begin{gathered}
\varepsilon_{q y, u c}=\frac{J \delta \omega d^{\alpha /(1-\alpha)}}{A q^{s s} \bar{L} \frac{\alpha^{2}}{1-\alpha}\left(\alpha q^{s s}-\alpha n\right)^{\frac{\alpha}{1-\alpha}-1}+A \bar{L}\left(\alpha q^{s s}-\alpha n\right)^{\frac{\alpha}{1-\alpha}} \frac{y^{s s}}{q^{s s}}} \\
\varepsilon_{q y, c}=\frac{J \delta(d)^{\alpha /(1-\alpha)}}{q^{s s} \bar{L} D \frac{\alpha^{2}}{1-\alpha}\left(\alpha q_{s s}-\alpha n\right)^{\frac{\alpha}{1-\alpha}-1}+\bar{L} D\left(\alpha q^{s s}-\alpha n\right)^{\frac{\alpha}{1-\alpha}} \frac{y^{s s}}{q^{s s}}} \\
\varepsilon_{q i, u c}=\frac{(1-\omega)(1-\alpha) i^{s s}\left(q^{s s}-n\right)}{A\left(q_{s s}-n(1-\alpha)\right)} \\
\varepsilon_{q i, c}=\frac{m(1-\alpha) i^{s s}\left(q^{s s}-n\right)}{\omega \cdot D \cdot\left(q_{s s}-n \cdot(1-\alpha)\right)}
\end{gathered}
$$


where $\varepsilon_{q y, c}$ is the elasticity of price with respect to income in constrained economy, $\varepsilon_{q y, u c}$ is the elasticity of price with respect to income in unconstrained economy, $\varepsilon_{q i, c}$ is the elasticity of price with respect to interest rate in constrained economy $\varepsilon_{q i, u c}$ is the elasticity of price with respect to interest rate in unconstrained economy.

Calculations yield the following elasticities:

$$
\begin{aligned}
& \varepsilon_{q y, u c}=0.324 \\
& \varepsilon_{q y, c}=0.324 \\
& \varepsilon_{q y, u c}=0.324 \\
& \varepsilon_{q y, c}=0.324
\end{aligned}
$$

In this case the housing prices change in total by $40.2 \%$ due to a change in demandside factors.

Given between 1995 and 2006 housing prices changed by 53.5\%, the change in housing price due to supply shock should have been equal to $13.3 \%$. Now let us use the elasticity of housing prices with respect to regulation cost which is given by the following formula:

$$
\varepsilon_{q s}=\frac{\alpha n}{\left(q_{s s}-n(1-\alpha)\right)}
$$

Calculating this formula we get that $\varepsilon_{q s}=0,185$. This implies that building permit cost should have increased by $71.8 \%$ to match the actual change in housing price. Since the new building permit cost is equal to 13,160 dollars, the old one will be given by 7,660, which implies the change of building permit cost of 5,500 dollars. Now we will use all the changes of variables in units but not in percents to calculate the dollar value of welfare adjustment resulting from housing price appreciation driven by all factors jointly. Thus $\Delta_{n}=5,500, \Delta y_{\text {old }}=14,125, \Delta i_{c}=-1.95$ and $\Delta i_{u c}=-2.38$. Based on Global Property Guide we set transaction costs $f 1\left\{x^{s s} \neq 0\right\}$ to the $9.07 \%$ of housing price. Using all of the above information each of the welfare adjustments derived previously is calculated for both credit-constrained as well as unconstrained versions of the model. Results are summarized in Table 3.

Table 3

Welfare Adjustments tn the Constrained and Unconstrained Models (for different types of shocks)

\begin{tabular}{|c|c|c|}
\hline Adjustment & (c) Constrained & (uc) Unconstrained \\
\hline$\Delta y_{s}$ & 4560 & 3780 \\
\hline$\Delta y_{y}$ & -9950 & -10770 \\
\hline$\Delta y_{i}$ & -20360 & -5830 \\
\hline
\end{tabular}

Source: Own calculations.

According to prior expectations housing price appreciation driven by negative supply shock (building permit costs) results in welfare loss(positive $\Delta y$ ) while housing price appreciation driven by positive demand shock (income and interest rates) results 
in welfare improvement (negative $\Delta y$ ). Given these results it is easy to calculate the cumulative aggregate welfare change in the actual US economy 1995-2006. To make result more informative the final cumulative welfare adjustment per household is expressed in terms of median income in the US in 2006. Under such measurement the total aggregate welfare adjustment is given by:

$$
\Delta Y_{\text {aggregate }}=\frac{J_{c}}{J_{u c}+J_{c}} \frac{\left(\Delta y_{s, c}+\Delta y_{y, c}+\Delta y_{i, c}\right)}{y_{\text {median }}}+\frac{J_{u c}}{J_{u c}+J_{c}} \frac{\left(\Delta y_{s, u c}+\Delta y_{y, u c}+\Delta y_{i, u c}\right)}{y_{\text {median }}}=-0.278
$$

In this formula $\Delta y_{s, c}$ is welfare adjustment in the constrained economy due to housing price appreciation caused by supply shock, $\Delta y_{s, u c}$ is welfare adjustment in the unconstrained economy due to housing price appreciation caused by the supply shock in the unconstrained economy, $\Delta y_{y, c}$ is welfare adjustment in the constrained economy due to housing price appreciation caused by income shock, $\Delta y_{y, u c}$ is welfare adjustment in the unconstrained economy due to housing price appreciation caused by income shock, $\Delta y_{i, c}$ is welfare adjustment in the constrained economy due to housing price appreciation caused by interest rate shock, $\Delta y_{i, u c}$ is welfare adjustment in the unconstrained economy due to housing price appreciation caused by interest rate shock in the unconstrained economy. Since the sign of the adjustment is negative the result implies the improvement in aggregate welfare. Thus, the housing price appreciation which took place in the US economy between 1995 and 2006 and which was driven by an observed combination of demand and supply side shocks improved the aggregate welfare per household by around $28 \%$ of mean household income in 2006 per household.

\section{Summary}

This paper explores the aggregate welfare effects of housing price appreciation in a general model with binding credit constraints and endogenous housing prices. First, the model with exogenous housing prices but with households subject to binding credit constraints is considered. It is demonstrated that in an economy with binding credit constraints housing price appreciation leads to an improvement in aggregate welfare. The result is due to the fact that credit-constrained model takes into account the welfare improving effect of the housing price appreciation, which implies relaxation of binding credit constraints. This effect is ignored in the previous models where households are assumed to be unconstrained.

A model with endogenous housing price, in which housing price appreciation is driven by supply and demand side shocks, is analyzed for both credit-constrained and unconstrained households. The supply side shocks are driven by the increases in building permit cost. Changes in income and interest rates are the demand side drivers. The relationship between welfare adjustments in the two modelling alternatives depends on the relative weight housing in the agent's utility function. The theoretical models are calibrated to calculate the actual welfare adjustment resulting from the combination of all considered shocks in the US housing market in 1995-2006. It is shown that the housing price appreciation from 1995 to 2006 led to per household improvement in the aggregate welfare by an amount equivalent to approximately $22 \%$ of mean household income in 2004. 


\section{References}

Aghion, P., Bachetta, P. (2004), "Financial Development and the Instability of Open Economies." NBER Working Paper Series No. 10246.

Amin, K., Capozza, D. (1993), "Sequential Development." Journal of Urban Economics Vol. 34, No. 2, pp. 142-158.

Bajari, P., Lanier Benkard, C., Krainer J. (2005), "House Prices and Consumer Welfare." Journal of Urban Economics, Vol. 58, No. 3, pp. 474-488.

Campbell J., Cocco J. (2005), "How Do House Prices Affect Consumption? Evidence from micro data." NBER Working Paper Series No. 11534.

ECB (2003), Structural Factors in the EU Housing Market. Frankfurt am Main: European Central Bank.

Federal Housing Finance Board Agency (2009), Monthly Interest Rate Survey. Washington: Federal Housing Finance Board Agency.

Glaeser E., Gyourko, J. (2005), "Why Have Housing Prices Gone up?" American Economic Review, Vol. 95, No. 2, pp. 329-359.

lacoviello, M. (2004), "Consumption, House Prices and Collateral Constraints: Structural Econometric Analysis." Boston College Department of Economics, Boston College Working Papers in Economics No. 589.

lacoviello, M. (2005), "House Prices, Borrowing Constraints and Monetary Policy in the Business Cycle" American Economic Review, Vol. 95, No. 3, pp. 739-764.

lacoviello, M., Minetti, R. (2003), "Financial Liberalisation and the Sensitivity of House Prices to Monetary Policy: Theory and Evidence." Boston College Department of Economics, Boston College Working Papers in Economics No. 538.

Kiyotaki, N., Moore, J. (2005), "Credit Cycles." Journal of Political Economy, Vol. 105, No. 2, pp. 211-248.

Lehnert, A. (2004), "Housing, Consumption and Credit Constraints." Staff working paper in the Finance and Economics Discussion Series No. 2004-63.

Li, W., Yao, R. (2005), "The Life Cycle Effects of House Price Changes." Federal Reserve Bank of Philadelphia, Working Papers No. 05-7.

Malpezzi, M., Ozanne, L., Thibodeau, T. (1987), "Microeconomic Estimates of Housing Depreciation." Land Economics, Vol. 63, No. 4, pp. 372-385.

Margolis, S. (1982), "Housing depreciation: An Empirical Consideration of the Filtering Hypotheses." Review of Economics and Statistics, Vol. 64, No. 1, pp. 90-96.

McFarlane, A. (2001), "Rent Stabilization and the Long-Run Supply of Housing." US Department of Housing and Urban Development, ECON Working Paper No. 0109001.

Mendoza, G., Durdu, C. (2004), "Putting the Brakes on Sudden Stops: The Financial Frictions-Moral Hazard Tradeoff of Asset Price Guarantees." NBER Working Paper Series No. 10790.

National Association of Realtors (2009), Existing-Home Sales Series. Chicago: National Association of Realtors.

Ortalo-Magne, F., Rady, S. (2006), "Housing Market Dynamics: On the Contribution of Income Shocks and Credit Constraints." Review of Economic Studies, Vol. 73, No. 2, pp. 459-485.

Tsatsaronis, K., Zhu, H. (2004), "What Drives Housing Price Dynamics: Cross-Country Evidence." BIS Quarterly Review, Vol. (year) 2004, No. 3, pp. 65-78.

US Census Bureau (2009), Historical Income Tables. Washington: US Census Bureau.

U.S. Department of Commerce (2009), Current Population Report. Washington: U.S. Department of Commerce. 